\title{
Sigmoidoscopic and radiological study of the recto-sigmoid junction
}

\author{
R. V. CLARK, I. GREY THOMAS, AND A. D. ROY \\ From the Departments of Surgery and Radiodiagnosis, Western Infirmary, Glasgow
}

EDITORIAL SYNOPSIS This study demonstrates that the 'sigmoidoscopic' recto-sigmoid junction coincides with the 'radiological' junction between the rectum and the sigmoid colon.

Adequate investigation of the left side of the large bowel and the rectum requires examination by sigmoidoscope and by barium enema. In the lower pelvic colon and the upper rectum these investigations are complementary and sigmoidoscopy may give a clue to disease higher up. Welin (1958) is of the opinion that, using the double contrast method, barium examination of the rectum is in many cases superior to proctoscopy. However, doubt remains whether these investigations overlap and whether the 'sigmoidoscopic' recto-sigmoid junction is the same as the 'radiological' recto-sigmoid junction or whether there is a gap between them. In an attempt to resolve this doubt a method of marking the bowel at sigmoidoscopy was devised so that levels could be indicated to the radiologist. This method is also of value in marking lesions seen at sigmoidoscopy for subsequent radiological investigation.
METHOD

Spencer, Jackman, and Witten (1962) had described a malleable ring which could be applied to polyps with a special forceps but the following method was devised using available instruments. Michel clips were attached to the mucosa as a marker. A clip, slightly angled, fits neatly into the cupped jaws of the Officer rectal biopsy forceps (Fig. 1) and can be easily applied with them. The hazards of the procedure were first studied on two patients about to undergo abdominoperineal resection. The sigmoidoscope was passed and two clips were attached to the bowel wall in each case. One clip was inserted as deeply as possible and with the other an attempt was made to attach it only to mucosa. Examination of the excised rectums showed that although a good bite had been taken by the deeply inserted Michel clips, the bowel wall had not been penetrated. Inspection of the mucosal clip showed that the teeth of the clip had penetrated only mucosa, submucosa, and a few fibres of the inner layer

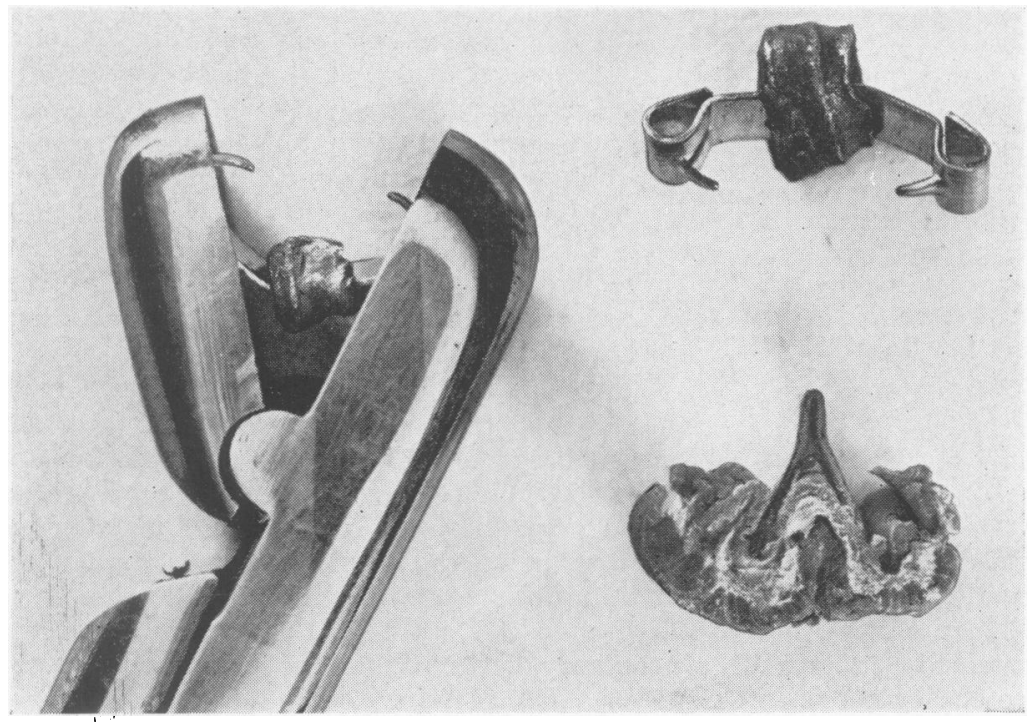

509
FIG. 1. The Officer biopsy forceps with lead tagged clip and clip applied to the mucosa. 
of muscle (Fig. 1). The levels at which these clips had been applied were noted at sigmoidoscopy and measurements on the excised specimens between the clips and anal margin were found to tally with the sigmoidoscope length to within $0.5 \mathrm{~cm}$.

These two cases showed that the depth to which the clip was inserted could be controlled and perforation of the normal bowel wall was unlikely. However retention of the clip might also be harmful, so all patients who had clips attached were radiographed a week later and no clips had been retained. All patients were told that their bowel had been marked with a clip and none reported any ill effects.

At sigmoidoscopy the recto-sigmoid junction was taken as the point at which the rectum narrowed and the sigmoidoscope changed direction, pointing more anteriorly and towards the left iliac fossa. Clips were attached at this point and then the patients were examined by a modified technique with dilute barium.

\section{RADIOLOGICAL TECHNIQUE}

The purpose of the $x$-ray examination was to demonstrate the relative positions of the recto-sigmoid junction as marked by the clip at sigmoidoscopy and as seen radiologically after the rectum and sigmoid had been distended with barium introduced per rectum.

Visualization of the clip on the screen presented no difficulty when the patient lay supine. However, the recto-sigmoid junction is only demonstrated with the patient lying in the left oblique or lateral position. In this position the clip could not be identified by screening although clearly seen on the film. For this reason, and also to give better contrast against the barium, a piece of lead was tagged on to the clip (Fig. 1). Despite this, normal strength barium still completely obscured the clip and it was found necessary to dilute it. A standard mixture of $60 \mathrm{oz}$. of Micropaque made up to 3 pints with water was then diluted by using one part of this mixture to four of water. This strength gave sufficient contrast to outline the rectum and sigmoid and to be visible on the screen.

All films were taken with the undercouch tube. The final method adopted was as follows:

With the patient lying supine the clip was identified on the screen. The patient was then turned to the left in the oblique or lateral position, whichever he found easier to maintain. A $12 \times 10$ in. film was taken of the rectosigmoid region. Maintaining this position barium was introduced per rectum and when it was seen to enter the descending colon a further $12 \times 10 \mathrm{in}$. film was taken and the enema stopped. After evacuation the patient again lay in the same lateral or oblique position as previously and a further $12 \times 10 \mathrm{in}$. film was taken.

\section{RESULTS}

Twenty-four cases were examined. It was found that in all cases the clip was still present when the patient was screened and in most cases, in the post-evacuation film. Twelve of the studies had to be discounted either because they belonged to the earlier group

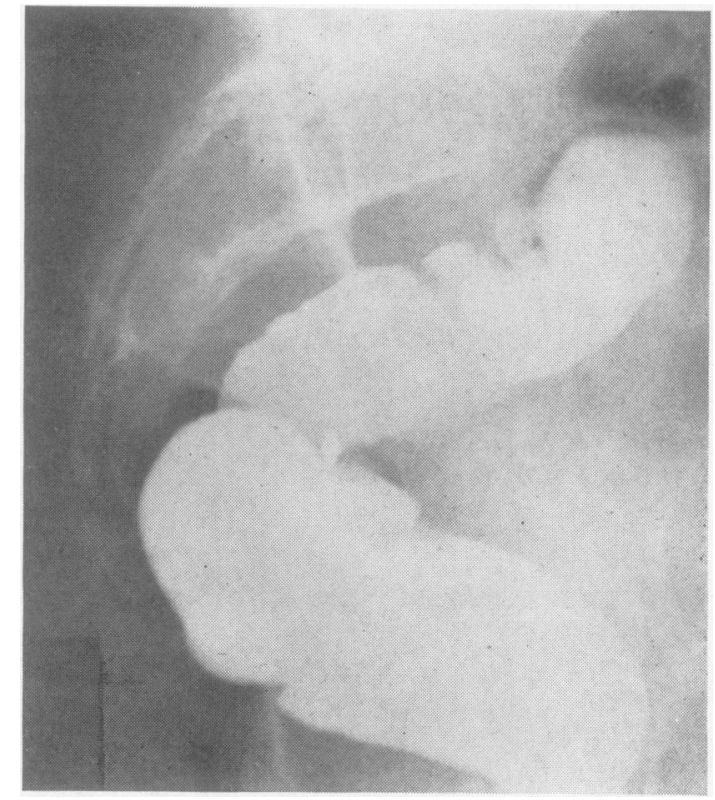

FIG. 2. Rectum distended with barium showing clip at the recto-sigmoid junction opposite the fourth sacral segment.

examined, before the barium had been diluted, or because the patient failed to return for the postevacuation film.

Twelve cases are therefore judged suitable for evaluation. In nine of these the recto-sigmoid junction, as marked by the clip at sigmoidoscopy and demonstrated radiologically, coincided (Fig. 2). There was usually a slight change in position relative to the sacrum between the position of the clip before and after the rectum and sigmoid were outlined with barium. After filling, the clip was seen to move slightly anteriorly and to lie at a higher level. In the post-evacuation film the clip had returned to approximately its initial position. The anatomist usually regards the rectum as beginning opposite the third piece of the sacrum (Grant, 1958) but in all these studies the recto-sigmoid junction lay at the level of the fourth piece of the sacrum and the distance from the anus to the clip as measured at sigmoidoscopy lay between 12 and $14 \mathrm{~cm}$.

The findings in the three remaining patients merit individual mention. In the first patients there was considerable change in position of the clip before and after the barium had been run in. This clip had been applied $2 \mathrm{~cm}$. above the recto-sigmoid junction and when the bowel was distended with barium the distension of the upper rectum and lower sigmoid straightened the bowel and therefore produced a discrepancy between the two positions (Figs. 3a and $b$ ). 

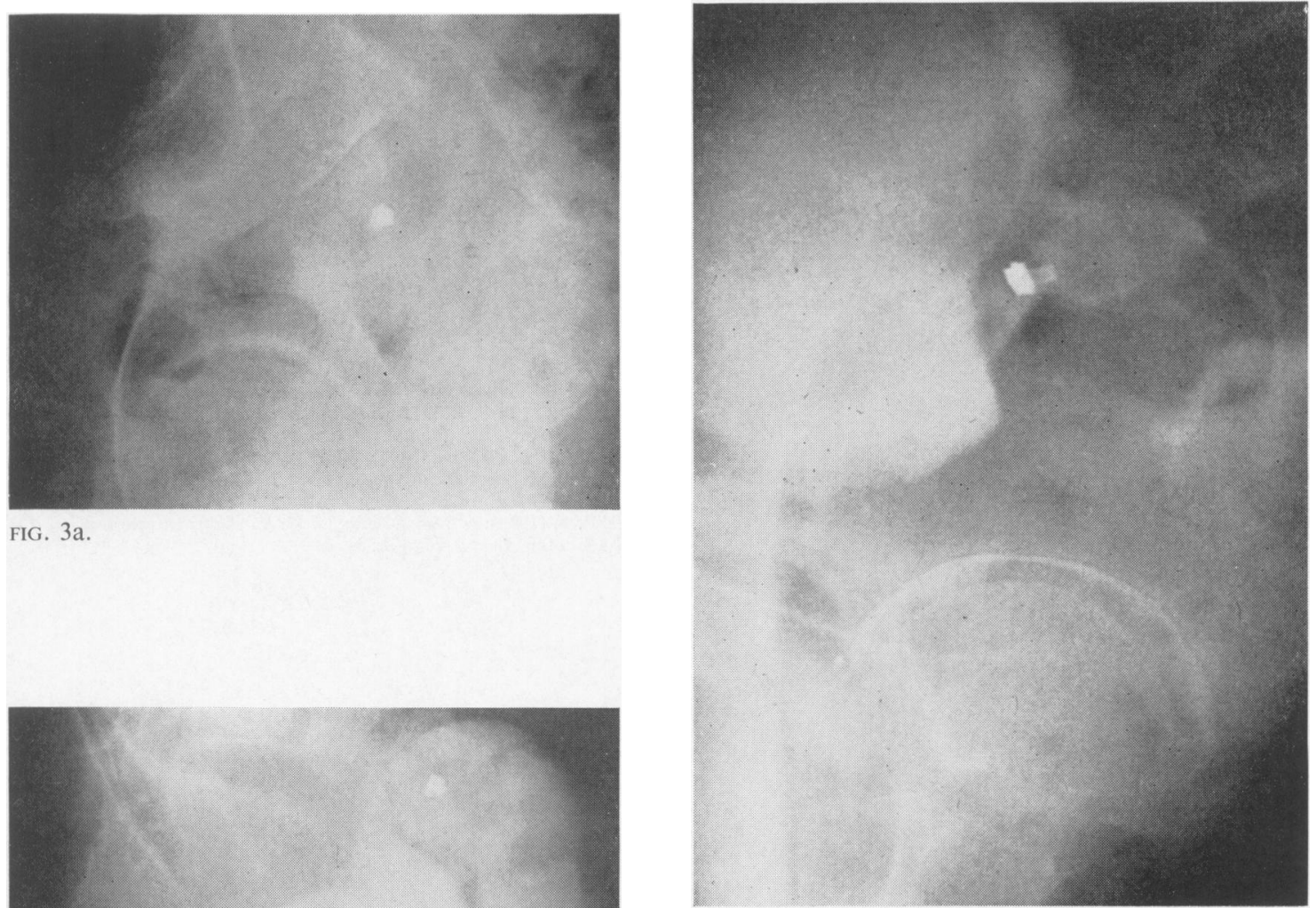

FIG. 4.

FIG. 3. Clip applied $2 \mathrm{~cm}$. above the recto-sigmoid junction $(a)$ before barium enema and $(b)$ rectum distended with barium.

FIG. 4. Clip at lower border of the rectal carcinoma after barium enema.

FIG. 5. Post-evacuation film showing clip and diverticula.

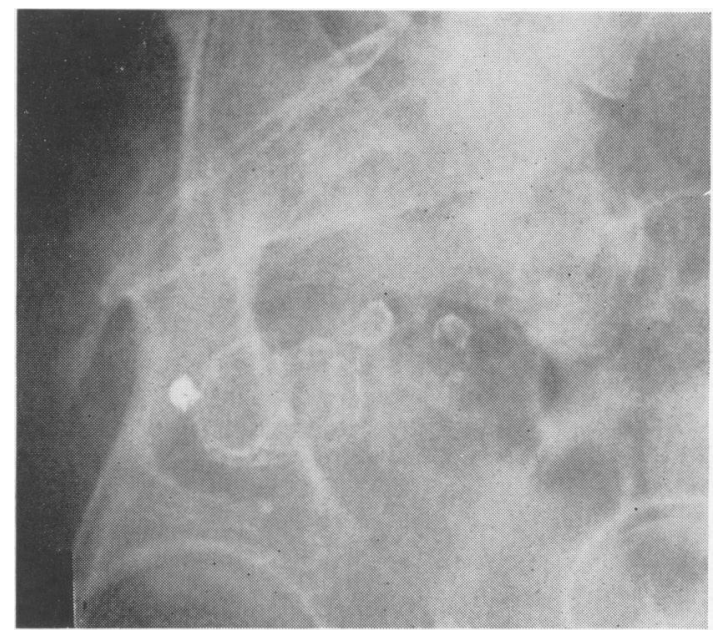

FIG. 5. 
In a second patient the clip was inserted at the lower level of a carcinoma of the rectum. The position of the clip coincided with the lower level of the lesion seen radiologically (Fig. 4).

In the third patient a polyp seen at the rectosigmoid junction on sigmoidoscopy was removed and its position marked by the clip. The position of the clip coincided with the radiological recto-sigmoid junction and no other polyps were detected by the radiologist though diverticulae were demonstrated higher up (Fig. 5).

\section{CONCLUSIONS}

Michel clips applied in the way described are a safe and effective method of marking levels and lesions during sigmoidoscopic examination.
With multiple lesions of the rectum and sigmoid colon those seen sigmoidoscopically can be tagged and correlated with or differentiated from those seen in the radiological investigation.

The recto-sigmoid junction as seen through the sigmoidoscope coincides with the radiological recto-sigmoid junction.

Our thanks are due to Mr. Gabriel Donald for the preparation of the photographs and to Professor A. W. Kay for advice in the preparation of this paper.

\section{REFERENCES}

Grant, J. C. B. (1958). A Method of Anatomy, p. 353. Williams and Wilkins, Baltimore.

Spencer, R. J., Jackman, R. J., and Witten, D. M. (1962). New device for delineating polyps of lower bowel. Proc. Mayo Clin., 37, 451-453.

Welin, S. (1958). Modern trends in diagnostic roentgenology of the colon. Brit. J. Radiol., 31, 453.

\section{The August 1965 Issue \\ THE AUGUST 1965 ISSUE CONTAINS THE FOLLOWING PAPERS}

An epidemiological study of ulcerative colitis and regional enteritis in the Oxford area J. G. EVANS and E. D. ACHESON

Upper intestinal motility in ulcerative colitis, idiopathic steatorrhoea, and the irritable colon syndrome J. A. RITCHIE and S. N. SALEM

Action of 5-hydroxytryptamine on the human stomach, duodenum, and jejunum in vitro D. J. FISHLOCK, A. G. PARKS, and J. VERONICA DEWELL

Effect of L-thyroxine on gastric secretion in the pylorusligated rat D. W. BLAIR, M. J. WILLIAMS, A. J. CARR, and S. J. KILPATRICK

Effect of ammonium chloride and urea infusions on ammonium levels and acidity of gastric juice BERTRAM FLESHLER and GEORGE J. GABUZDA

Intracellular enzymatic histochemistry of the human stomach with special reference to atrophic gastritis H. RAGINS and M. DITTBRENNER

Studies with the maximal histamine test B. J. VAKIL and A. M. MULEKAR
Radiological diagnosis of gastritis W. B. JAMES, A. G. MELROSE, J. W. DAVIDSON, and R. I. RUSSELL

'Chronic duodenitis': A clinical pathological entity? I. T. BECK, D. S. KAHN, M. LACERTE, J. SOLYMAR, U. CALLEGARINI, and M. C. GEOKAS with the assistance of E. PHELPS

Chemical analysis of an enterolith P. FANTL, A. J. ROLLO, and H. STROSBERG

Glucose and fructose absorption in idiopathic steatorrhoea C. D. HOLDSWORTH and A. M. DAWSON

The pharynx and oesophagus in dystrophia myotonica J. W. PIERCE, B. CREAMER, and V. MaCDERMOT

Some aspects of anal continence and defaecation S. F. PHILLIPS and D. A. W. EDWARDS

Assessment of a new inlet device for use in gastric hypothermia L. H. BLUMGART, F. D. NAYLOR, and H. L. DUTHIE

Copies are still available and may be obtained from the PUBLISHING MANAGER, BRITISH MEDICAL ASSOCIATION, TAVISTOCK SQUARE, W.C.I. price 18s. 6D. 